\title{
Sensitivity and specificity of polymerase chain reaction in Giemsa- stained slides for diagnosis of visceral leishmaniasis in children
}

\author{
Yvone Maia Brustoloni ${ }^{+}$, Rosimar Batista Lima* , Rivaldo Venâncio da Cunha**, \\ Maria Elizabeth Dorval***, Elisa Teruya Oshiro***, Ana Lúcia Lyrio de Oliveira, \\ Claude Pirmez*
}

\begin{abstract}
Departamento de Pediatria **Departamento de Clínica Médica ***Departamento de Patologia, Universidade Federal de Mato Grosso do Sul, Caixa Postal 102, 79080-190 Campo Grande, MS, Brasil *Laboratório de Imunopatologia, Instituto Oswaldo CruzFiocruz, Rio de Janeiro, RJ, Brasil

The aim of this study was to evaluate the sensitivity and specificity of polymerase chain reaction (PCR) in the detection of Leishmania DNA in archived Giemsa-stained bone marrow slides for diagnosis of visceral leishmaniasis (VL), and to compare PCR with conventional diagnostic techniques, like direct microscopy and parasite culture. Specimens of archived Giemsa-stained bone marrow slides from 91 patients with VL and from 79 controls with other diseases or conditions were studied. PCR showed the highest sensitivity (92.3\%) and had good specificity (97.5\%). Direct examination detected $79.1 \%$ and culture $59 \%$ of positive samples. In addition, PCR was able to detect VL in 16 of 19 patients (84.2\%) with negative microscopy. PCR in Giemsa-stained bone marrow slides is a suitable tool for confirming diagnosis in patients with $V L$ and may be useful in the diagnosis of difficult cases. Slide smears are easily stored, do not require special storage conditions such as low temperatures, and can be easily mailed to centers where PCR is available, making it an excellent option for diagnosis in the field.
\end{abstract}

Key words: visceral leishmaniasis - polymerase chain reaction - diagnosis

Conventional methods for diagnosis of visceral leishmaniasis (VL), such as parasitological or serological tests, still have limitations in their use (Sundar 2003, da Silva et al. 2005). The identification of the causal agent of human leishmaniasis by these tests is difficult even in a well-equipped hospital and improved tools for this purpose are needed.

Polymerase chain reaction (PCR) has now revolutionized contemporaneous etiologic diagnosis of infectious diseases. The description of species-specific kinetoplast DNA minicircles sequences (kDNA) (Kennedy 1984), with the possibility of amplification by PCR, made viable the utilization of the method for diagnosis of leishmaniasis in the early 1990s (Rodgers et al. 1990, Smyth et al. 1992). Currently, PCR techniques have been employed with a high level of accuracy by several researchers (Salotra et al. 2001, Cortes et al. 2004, De Doncker et al. 2005, Stark et al. 2006).

Various biological samples have been used for diagnosis of visceral or cutaneous leishmaniasis by PCR: bone marrow (Piarroux et al. 1994, Osman et al. 1997, Cortes et al. 2004), human (Lachaud et al. 2001, Cascio et al. 2002) and canine blood (Lachaud et al. 2002a), lymph nodes (Lachaud et al. 2002b), buffy coat (Lachaud et al. 2001), canine conjunctival or dermal scrapings

+ Corresponding author: brustoloni@uol.com.br

Received 24 November 2006

Accepted 29 March 2007
(Lachaud et al. 2002b), and skin or mucosal biopsies (Pirmez et al. 1999, Stark et al. 2006). Moreover, PCR has made possible the use of dried or old materials: Leishmania DNA has been extracted and amplified from blood or bone marrow aspirates spotted on filter paper (Cortes et al. 2004, da Silva et al. 2004), paraffin-embedded tissues (Lanús et al. 2005), Giemsa-stained slides (Motazedian et al. 2002), and museum specimens (Costa 1998)

In Mato Grosso do Sul, Center-West region of Brazil, the Federal University Hospital (NHU-UFMS) situated in the capital Campo Grande is a reference center for diagnosis and treatment of VL, receiving patients from various cities of the state for diagnostic confirmation or exclusion. The aim of this study was to evaluate the use of PCR in VL diagnosis using archived Giemsastained bone marrow aspirate (BMA) slides, establishing its sensitivity and specificity, and to compare the performance of this retrospective diagnosis with direct microscopy and culture.

Ninety-one children from the state of Mato Grosso do Sul, admitted for diagnosis and treatment of VL at the NHU-UFMS from January 1998 to September 2004 were studied. Diagnosis of VL was based on a suggestive clinical presentation, associated with a positive BMA direct microscopy or culture or serology by indirect immunofluorescence antibody test (IFAT) $\geq 1: 40$; children with a suggestive clinical picture whose laboratorial tests were negative but who responded to a therapeutic trial with antimonials were included too. Controls consisted of 79 children or adults who had a BMA performed for diagnostic purposes and who did not have a confirmed leishmaniasis diagnosis but other diseases or conditions were detected. Table I shows the characteristics of the children with VL and of controls. 
TABLE I

Characteristics of patients with visceral leishmaniasis and controls

\begin{tabular}{ll}
\hline Patients with visceral leishmaniasis & 91 \\
Age & $6 \mathrm{~m}-13 \mathrm{y}($ mean $=4 \mathrm{y})$ \\
Sex & $51(56 \%) / 40(44 \%)$ \\
Male / Female & 79 \\
Controls & $12 \mathrm{~m}-75 \mathrm{y}(\mathrm{mean}=31 \mathrm{y})$ \\
Age & \\
Sex & $36(45.6 \%) / 43(54.4 \%)$ \\
Male / Female & \\
Diseases or conditions & $28(35.4 \%)$ \\
Leukemias & \\
Idiopathic thrombocy- & $14(17.7 \%)$ \\
topenic purpura & $5(6.3 \%)$ \\
Splenomegaly & $5(6.3 \%)$ \\
Bacterial infections & $5(6.3 \%)$ \\
Normal bone marrow & $4(5.0 \%)$ \\
Lymphoma & $3(3.8 \%)$ \\
Multiple myeloma & $3(3.8 \%)$ \\
Systemic lupus erythematosus & $2(2.5 \%)$ \\
Bone marrow aplasia & $2(2.5 \%)$ \\
Myelodysplastic syndrome & $8(10.1 \%)$ \\
Other &
\end{tabular}

m: months; y: years.

BMAs were collected for occasion of admission, by sternal puncture or more rarely from the posterior iliac crest. Four Giemsa-stained slides for each patient were analyzed by direct microscopic examination with a $10 \mathrm{X}$ eyepiece and a 100X oil objective. More than 1000 microscopic fields were examined, when necessary; before deciding for a negative result, the entire slides were viewed. The slides were then archived at room temperature in the sectors of Parasitology or Hematology. Cultures were performed with Novy-MacNeal-Nicolle (NNN) with Schneider's insect medium, incubated at $24^{\circ} \mathrm{C}$, and weekly examined by microscopy for the presence of parasites until eight weeks. IFAT, when possible, was performed with a commercial kit for the diagnosis of human leishmaniasis (Bio-Manguinhos-Fiocruz).

For DNA extraction archived Giemsa-stained bone marrow slides were cleaned with tissue paper, wetted with sterile water, and scraped with a sterile scalpel. The material was added to $300 \mu \mathrm{l}$ of sterile water, and a GenomicPrep $^{\mathrm{TM}}$ Blood DNA Isolation Kit (Amersham Pharmacia Biotech) was used, according to the manufacturer's instructions, except that the final elution volume was reduced to $20 \mu \mathrm{l}$.

The DNA target for PCR amplification was the conserved region of the minicircle molecule (kinetoplastid mitochondrial DNA; kDNA), using a "hot-start" PCR technique. Briefly, each reaction contained $5 \mathrm{ml}$ of $10 \mathrm{X}$ buffer (Promega), $100 \mathrm{ng}$ of 5' and 3' oligonucleotide primers (primer A: $5^{\prime}-(\mathrm{G} / \mathrm{C})(\mathrm{G} / \mathrm{C})(\mathrm{C} / \mathrm{G}) \mathrm{CC}(\mathrm{A} / \mathrm{C})$ CTAT(A/T)TTACACCCACCCC-3'; primer B: 5'GGGGTAGGGGCGTTCTGCGAA-3'), $200 \mathrm{mM}$ of each deoxynucleoside triphosphate (Promega), 1.5-mM $\mathrm{MgCl}_{2}, 2.5 \mathrm{U}$ of Taq polymerase (Perkin Elmer), sterile water, and $2 \mu \mathrm{l}$ of the DNA sample. PCR was performed in a total reaction volume of $50 \mu \mathrm{l}$, under the following conditions: a first heating step of $4 \mathrm{~min}$ at $94^{\circ} \mathrm{C}$, followed by 30 cycles of $30 \mathrm{~s}$, each consisting of denaturation at $94^{\circ} \mathrm{C}$, annealing at $50^{\circ} \mathrm{C}$, and extension at $72^{\circ} \mathrm{C}$, with a final elongation at $72^{\circ} \mathrm{C}$ for $10 \mathrm{~min}$. A negative control without DNA in the mixture and a positive control containing 80fg of Leishmania DNA were included in each experiment.

Ten microliters of the amplified products were analyzed by electrophoresis in a $2 \%$ agarose gel stained with ethidium bromide $(0.5 \mu \mathrm{g} / \mathrm{ml})$ and visualized under UV. A 50-bp or 100-bp DNA ladder (Promega) was used as a marker. Samples were considered as positive when a PCR of $120 \mathrm{bp}$ could be detected.

PCR and direct microscopy were performed in all patients with VL and controls. Cultures were obtained in 88 children with VL and were just performed for those controls with splenomegaly, bacterial infections, normal bone marrow, or other conditions $(n=23)$, but not for those who had a confirmed diagnosis of hematological disease. Serology was possible to be obtained in 58 children with VL.

For the 91 patients, diagnosis was based on positive direct examination $(n=72)$, culture $(n=5)$, serology $(n$ $=7$ ) or response to therapy with antimonies $(n=7)$.

The study was conducted upon approval by the Ethics Committee of the Federal University of Mato Grosso do Sul and was in agreement with the regulations of the Brazilian Ministry of Health.

Table II describes the results of the diagnostic methods employed. Among the 91 children with a diagnosis of VL, PCR was positive in 84 , yielding a sensitivity of 92.3\% (84.3-96.6, 95\% CI). PCR specificity was $97.5 \%$ (90.3-99.6, 95\% CI), since two out of the 79 patients with other diseases, in the control group, were positive to VL. Positive and negative predictive values were 97.7\% (91.1-99.6, 95\% CI) and 91.7\% (83.0-96.3, 95\% CI), respectively.

The present experiment suggests that it is possible to reach a retrospective diagnosis of visceral leishmaniasis from stored Giemsa-stained bone marrow slides. PCR allowed the retrieval of archival cases, since the test showed a high sensitivity and specificity.

The inclusion of patients in the absence of a goldstandard diagnosis may have important consequences when the sensitivity of a method is being evaluated. Analyzing only those children with a positive parasitological test (direct examination or culture: $n=77$ ), PCR was positive in 73 , thus increasing its sensitivity to $94.8 \%$ (86.5-98.3, 95\% CI). Considering that we used dried, old materials for the extraction of DNA, some of them archived for as long as six years, the sensitivity achieved was highly satisfactory.

The good performance of the assay was reflected too in its ability to detect DNA of the parasite in 16 of 19 patients $(84.2 \%)$ for whom direct microscopy was negative. Moreover, in the seven patients whose diagnoses were based only on clinical criteria and a favorable response to antimony (with no positive parasitological or 
TABLE II

Bone marrow aspirate (BMA) microscopy, culture, and polymerase chain reaction (PCR) in patients with visceral leishmaniasis and controls

\begin{tabular}{lcccc}
\hline & \multicolumn{2}{c}{ Patients $(\mathrm{n}=91)$} & \multicolumn{2}{c}{ Controls $(\mathrm{n}=79)$} \\
& $\mathrm{n}$ tested & $\mathrm{n}$ positive $(\%)$ & $\mathrm{n}$ tested & \multicolumn{2}{c}{$\mathrm{n}$ positive $(\%)$} \\
\hline BMA microscopy & 91 & $72(79.1)$ & 79 & 0 \\
Culture & 88 & $52(59.0)$ & 23 & 0 \\
PCR & 91 & $84(92.3)$ & 79 & $2.5)$ \\
\hline
\end{tabular}

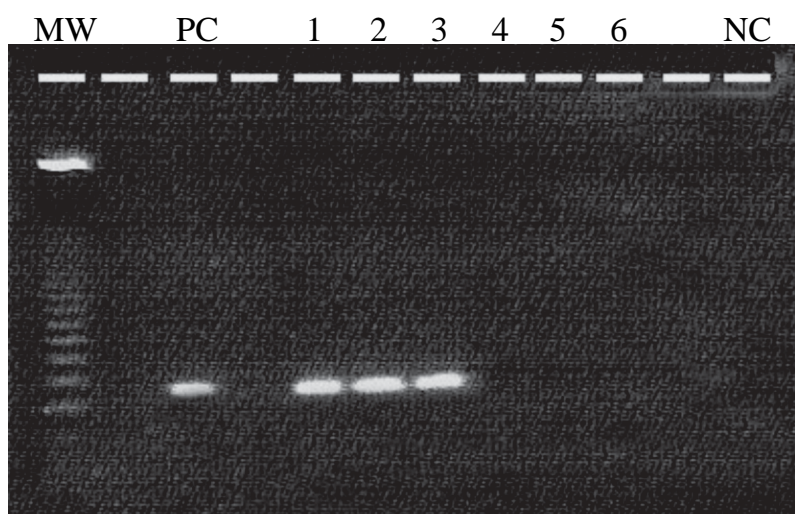

Polymerase chain reaction amplification products of bone marrow Giemsa-stained slides. MW: 100 bp DNA ladder size marker; PC: positive control; 1, 2, 3: patients with visceral leishmaniasis; 4, 5, 6: patients with other diseases; NC: negative control.

serological proof), PCR was positive in four (57\%), showing that the method may be helpful in the diagnosis of difficult cases.

Negative PCR results have been reported in a few patients with positive parasitological proof (Piarroux et al. 1994, Cortes et al. 2004). Similarly, four of our patients with a positive microscopic examination had a negative PCR, which can be explained by the fact that we used slides that had been stored for many years, and DNA in these smears may have suffered some damage.

In the control group we included a great number of patients whose differential diagnosis with VL is frequently required; PCR was positive in two patients without VL. The possibility of asymptomatic carriers has been suggested in such situations (Salotra et al. 2001). Although the occurrence of false positives because of contamination is unlikely, it cannot be ruled out too.

DNA extraction and amplification of Leishmania by PCR in Giemsa-stained slides archived for up to four years was attempted with success for the diagnosis of cutaneous leishmaniasis (Motazedian et al. 2002), showing the feasibility of establishing a new strategy for studying archived materials. Similarly to specimens collected on filter paper, slides can be easily stored, do not require low-temperature facilities for conservation, and can be easily mailed to reference centers for diagnostic confirmation or exclusion. The possibility of elucidating cases of VL for which no previous diagnostic proof is available is an encouraging step towards the inclusion of PCR in the current diagnosis of the disease.

\section{REFERENCES}

Cascio A, Calattini S, Colomba C, Scalamogna C, Galazzi M, Pizzuto M,Camilli R, Gramiccia M, Titone L, Corbellino M, Antinori S 2002. Polymerase chain reaction in the diagnosis and prognosis of Mediterranean visceral leishmaniasis in immunocompetent children. Pediatrics 10: E27.

Cortes S, Rolão N, Ramada J, Campino L 2004. PCR as a rapid and sensitive tool in the diagnosis of human and canine leishmaniasis using Leishmania donovani s.l.-specific kinetoplastid primers. Trans R Soc Trop Med Hyg 98: 12-17.

Costa LMC 1998. Leishmaniose Tegumentar Americana: Uso de Técnicas de Biologia Molecular no Diagnóstico de Infecção de Roedores da Coleção do Museu Nacional, Thesis, Escola Nacional de Saúde Pública, Rio de Janeiro, 70 pp.

da Silva ES, Gontijo CM, Pacheco Rda S, Brazil RP 2004. Diagnosis of human visceral leishmaniasis by PCR using blood samples spotted on filter paper. Genet Mol Res 3: 251-257.

da Silva MR, Stewart JM, Costa CH 2005. Sensitivity of bone marrow aspirates in the diagnosis of visceral leishmaniasis. Am J Trop Med Hyg 72: 811-814.

De Doncker S, Hutse V, Abdellati S, Rijal S, Singh Karki BM, Decuypere S, Jacquet D, Le Ray D, Boelaert M, Koirala S, Dujardin JC 2005. A new PCR-ELISA for diagnosis of visceral leishmaniasis in blood of HIV-negative subjects. Trans $R$ Soc Trop Med Hyg 99: 25-31.

Kennedy WP 1984. Novel identification of differences in the kinetoplast DNA of Leishmania isolates by recombinant DNA techniques and in situ hybridisation. Mol Biochem Parasitol 12:313-325.

Lachaud L, Chabbert E, Dubessay P, Dereure J, Lamothe J, Dedet JP, Bastien P 2002b. Value of two PCR methods for the diagnosis of canine visceral leishmaniasis and the detection of asymptomatic carriers. Parasitology 125: 197-207.

Lachaud L, Chabbert E, Dubessay P, Reynes J, Lamothe J, Bastien P 2001. Comparison of various sample preparation methods for PCR diagnosis of visceral leishmaniasis using peripheral blood. J Clin Microbiol 39: 613-617.

Lachaud L, Marchergui-Hammami S, Chabbert E, Dereure J, Dedet JP, Bastien P 2002a. Comparison of six PCR methods using peripheral blood for detection of canine visceral leishmaniasis. J Clin Microbiol 40: 210-215.

Lanús EC, Piñero JE, González AC, Valladares B, de Grosso ML, Salomón OD 2005. Detection of Leishmania braziliensis in human paraffin-embedded tissues from Tucumán, Argentina by polymerase chain reaction. Mem Inst Oswaldo Cruz 100: $187-192$.

Motazedian H, Karamian M, Noyes HA, Ardehali S 2002. DNA extraction and amplification of Leishmania from archived, 
Giemsa-stained slides, for the diagnosis of cutaneous leishmaniasis by PCR. Ann Trop Med Parasitol 96: 31-34.

Osman OF, Oskam L, Zijlstra EE, Kroon NC, Schoone GJ, Khalil ET, El-Hassan AM, Kager PA 1997. Evaluation of PCR for diagnosis of visceral leishmaniasis. J Clin Microbiol 35: 2454-2457.

Piarroux R, Gambarelli F, Dumon H, Fontes M, Dunan S, Mary C, Toga B, Quilici M 1994. Comparison of PCR with direct examination of bone marrow aspiration, myeloculture, and serology for diagnosis of visceral leishmaniasis in immunocompromised patients. J Clin Microbiol 32: 746-749.

Pirmez C, da Silva Trajano V, Paes-Oliveira Neto M, da-Cruz AM, Gonçalves-da-Costa SC, Catanho M, Degrave W, Fernandes O 1999. Use of PCR in diagnosis of human American tegumentary leishmaniasis in Rio de Janeiro, Brazil. $J$ Clin Microbiol 37: 1819-23.

Rodgers MR, Popper SJ, Wirth DF 1990. Amplification of kine- toplast DNA as a tool in the detection and diagnosis of Leishmania. Exp Parasitol 71: 267-75.

Salotra P, Sreenivas G, Pogue GP, Lee N, Nakhasi HL, Ramesh V, Negi NS 2001. Development of a species-specific PCR assay for detection of Leishmania donovani in clinical samples from patients with kala-azar and post-kala-azar dermal leishmaniasis. J Clin Microbiol 39: 849-854.

Smyth AJ, Ghosh A, Hassan MQ, Basu D, De Bruijn MH, Adhya S, Mallik KK, Barker DC 1992. Rapid and sensitive detection of Leishmania kinetoplast DNA from spleen and blood samples of kala-azar patients. Parasitology 105: 183-192.

Stark D, Pett S, Marriott D, Harkness J 2006. Post-kala-azar dermal leishmaniasis due to Leishmania infantum in a human immunodeficiency virus type 1 -infected patient. J Clin Microbiol 44: 1178-1180.

Sundar S 2003. Indian kala-azar-better tools needed for diagnosis and treatment. J Postgrad Med 4: 29-30. 